\title{
Figuras do direito na Fenomenologia do Espírito. A fenomenologia como doutrina do espírito objetivo?
}

\section{Figures du droit dans la Phénoménologie de l'Esprit. La phénoménologie comme doctrine de l'esprit objectif?*}

\author{
Jean-François Kervégan ${ }^{* *}$ \\ Tradução de Theresa Calvet de Magalhães ${ }^{* * *}$ \\ e Marcelo A. Cattoni de Oliveira****
}

A Fenomenologia do Espírito ocupa um lugar à parte na obra de Hegel; isso se comprova, muito simplesmente, quando se interroga sobre a posição que ela poderia ter no sistema hegeliano em sua organização definitiva, aquela que a Enciclopédia das Ciências Filosóficas apresenta, de modo muito condensado. É manifesto que o que se intitula aqui (nas $2^{a}$ e $3^{a}$ edições) "Fenomenologia do Espírito", a saber, o momento mediano da doutrina do espírito subjetivo que trata da consciência, só corresponde a uma parte, estreitamente circunscrita, do propósito da obra de 1807: os cinco primeiros capítulos, reagrupados eles mesmos em três seções que correspondem às três primeiras subdivisões da

\footnotetext{
J..F. Kervégan, "Figures du droit dans la Phénoménologie de l'Esprit. La phénoménologie comme doctrine de l'esprit objectif?", Revue internationale de philosophie, N. 240 (2007), p. 193-214. Nota dos Tradutores: a tradução foi feita da versão completa deste ensaio que nos foi enviada pelo Professor Jean-François Kervégan em 27 de outubro de 2010.

* Professor da Université Paris I - Panthéon Sorbonne (França). Membro senior do Institut Universitaire de France. Email: kervegan@univ-paris1.fr

*** Docteur em Sciences Politiques et Sociales pela UCL (Université Catholique de Louvain), Bélgica; Pós-doutorado em Filosofia Contemporânea no Institut Supérieur de Philosophie (UCL), em Louvain-la-Neuve (Bélgica); Docente colaborador do Programa de Pós-Graduação em Direito, Faculdade de Direito, da UFMG; Professora aposentada da UFMG (Departamento de Filosofia). Email: theresa.calvet@gmail.com

*.*** Mestre e Doutor em Direito (UFMG); Pós-Doutorado em Teoria do Direito (Roma TRE); Bolsista de Produtividade do CNPq (1D); Professor Associado IV e Subcoordenador do Programa de PósGraduação em Direito Faculdade de Direito da UFMG. Email: mcattoni@gmail.com
} 
"Fenomenologia do Espírito" da Enciclopédia: "A consciência como tal" (em 1807: "Consciência"), "A consciência de si" ou "A autoconsciência" (em 1807: idem), "A razão" (em 1807: idem). Podemos compreender então que reputados comentaristas tenham sido tentados a concluir que há um recobrimento global do plano da "Filosofia do Espírito" da Enciclopédia e do plano da Fenomenologia; o capítulo VI desta torna-se, então, um primeiro esboço da doutrina do espírito objetivo, e os capítulos VII e VIII uma antecipação da doutrina sistemática do espírito absoluto.

Sabemos, no entanto, notadamente graças aos trabalhos de P.J. Labarrière, que as coisas não são tão simples. Se examinarmos o capítulo VI da Fenomenologia, apercebemos que ele certamente aborda a maior parte dos objetos de que trata a doutrina do espírito objetivo (o direito abstrato, a moralidade, a eticidade, a família, o Estado ou a história do mundo), mas em uma ordem e, sobretudo, a partir de um ponto de vista que é substancialmente diferente daquele dos textos berlinenses. Esquematicamente, poderíamos dizer que as Grundlinien der Philosophie des Rechts e a Enciclopédia estudam a economia do espírito objetivo sob um ângulo estrutural, apresentando sucessivamente os componentes ou momentos abstratos deste (o direito e a moralidade), depois a totalidade subjetivo-objetiva concreta ("a eticidade") que disso resulta e que elas pressupõem ${ }^{1}$, enquanto que o capítulo $\mathrm{VI}$ da Fenomenologia expõe esses estratos do espírito objetivo sob a razão de uma história que é a história mesma, a do espírito em seu mundo ou do espírito como mundo: é assim a historicidade do espírito que se trata de pensar nisso que a opõe à anistoricidade da consciência, da consciência de si e, em um sentido, da razão, mas também à do espírito absoluto. Além disso, não é somente no capítulo VI que aparecem temáticas que pertencem à esfera do espírito objetivo: também as encontramos no capítulo IV (a mal denominada "dialética do senhor e do escravo", que Hegel trata sob o título "Dominação e servidão"), no capítulo V

A propósito desta dupla relação de posição e de pressuposição, ver RPh, W 7, § 33 e 256 A., p. 87 e 397-398; PPD, p. 142 e 332. 
("A efetuação da consciência de si racional por ela mesma", "A razão legisladora", "A razão legisprobatória") e até mesmo no capítulo VII (o desenvolvimento consagrado à "religião de arte" [Kunstreligion] ${ }^{2}$ retoma largamente a temática da Sittlichkeit antiga). Apercebemos assim que a obra inteira se desenvolve, por assim dizer, sobre um plano de corte em relação às divisões do sistema, de modo que cada uma delas encontrase por assim dizer difratada sobre todo seu espectro. Se isso é exato, seria vão buscar estabelecer entre "configurações" fenomenológicas e sequências enciclopédicas uma correspondência termo a termo. Mas é legítimo analisar aquelas como projeções ou como difrações destas.

É numa tal perspectiva que aqui se trata das "figuras do direito" na Fenomenologia. Que esta trata do direito, ao mesmo tempo no sentido usual (restrito) do termo e no sentido "extensivo" que lhe dá a doutrina do espírito objetivo ${ }^{3}$, isso é uma evidência; algumas das passagens as mais famosas da obra abordam, de fato, diretamente o problema do direito ou dos direitos, e de sua relação com a lei. Penso, é claro, na passagem intitulada "O estado de direito" (der Rechtszustand), mas também em "A lei do coração", "A virtude e o curso do mundo" e, de certa maneira, no conjunto do capítulo VI. Mas cabe sobretudo perguntar se não se trata então de um outro direito que o "direito dos juristas" (mas também, sem dúvida, do "direito dos filósofos"). Se pudermos ousar uma hipótese: é na medida mesma em que "o espírito", cujo processo de constituição e de advir a si a Fenomenologia do Espírito expõe, se distingue radicalmente daquilo que comumente se entende por esse termo, que se pode legitimamente tratar, no seio da "ciência do saber que aparece"4, e em várias fases desta, da questão do "direito", do direito no

2 Nota dos Tradutores: Labarrière traduz Kunstreligion por religion d'art ("religião de arte"): "Não se trata exatamente da religião da arte, mas da religião enquanto ela é marcada pela arte, pertence a seu domínio e se exprime através da arte. Traduzimos essa lexia tomando como modelo a expressão Kuntstwerk, "obra de arte" (...)" (PhE, p. 602, nota 2).

3 Ver RPh, W7, § 30 e A., p. 83; PPD, p. 139.

$4 \quad$ PhG, W3, p. 591; PhE, p. 695. 
sentido dos juristas, dos filósofos e dos deuses. Talvez seja necessário, então, compreender a presença insistente de temas "jurídicos" na Fenomenologia como uma manifestação da profunda redefinição do conceito de espírito à qual Hegel, ao escrevê-la, se atrelou.

\section{Por trás da consciência, o espírito}

A Fenomenologia do Espírito descreve de um modo não psicológico, ou ainda segundo sua estrutura universal, o "vir a ser da ciência em geral", isto é, o "longo caminho"5 que conduz da "consciência sensível" ao "saber absoluto"; esse caminho é feito de "experiências" sempre a retificar porque afetadas por uma discordância persistente entre a "certeza" que o sujeito tem de si mesmo e a "verdade" objetiva de suas representações de objetos, que pode ser avaliada de um ponto de vista recorrente. Esse ponto de vista (o für uns) é, grosso modo, o do sujeito objetivo do "saber absoluto" (termo que se presta, aliás, a contrassenso) ou da filosofia especulativa; ele se situa para além da oposição entre sujeito e objeto que estrutura a representação comum do que é o espírito, até mesmo nas formas filosoficamente sofisticadas que essa representação ganha em Kant e nos pós-kantianos. A abordagem fenomenológica exige, portanto, uma refundição do conceito clássico de espírito (Geist em alemão, mens em latim); é durante a redação mesma do livro que esta se opera, quando Hegel passa de um conceito de espírito classicamente indexado nas estruturas da consciência de objeto (que pressupõem elas mesmas um certo jogo com as [estruturas] da consciência de si reflexiva) a um conceito largo e desubjetivado, ousarse-ia quase dizer desespiritualizado, do que é o espírito. Hegel é, sem dúvida, o primeiro a conceber o espírito de modo outro que como uma certa função da subjetividade humana (a qual corresponde ao que ele denominará, na Enciclopédia, "espírito subjetivo"). O espírito não é nem

$5 \quad$ PhG, W3, p. 31; PhE, p. 89. 
uma substância (a res cogitans de Descartes), nem uma propriedade da "subjetividade" finita (do que se denomina comumente o sujeito), mas [é], assim como a ideia lógica ela mesma, da qual ele é a concretização, um processo:

"É somente quando consideramos o espírito no processo [...] da auto-efetuação do seu conceito, que nós o conhecemos em sua verdade (pois a verdade significa precisamente um acordo do conceito com sua efetividade). Em sua imediatidade, o espírito ainda não é verdadeiro, ele ainda não tornou o seu conceito objetivo, ele ainda não transformou o que nele está presente de maneira imediata em alguma coisa posta por ele, ele ainda não metamorfoseou sua efetividade em uma efetividade conforme ao seu conceito. O desenvolvimento total do espírito não é nada mais que seu ato de elevar-se ele mesmo à sua verdade". ${ }^{6}$

O espírito é um processo de Verwirklichung de seu conceito imediato ou de sua essência abstrata, os quais se identificam com a liberdade, sendo esta "a absoluta negatividade do conceito como identidade consigo". ${ }^{7}$ Essa determinação processual do espírito implica uma objetivação de sua determinação subjetiva primária: o espírito só é conforme ao seu conceito quando ele se objetiva sob a figura de um "mundo a produzir e produzido por ele, no qual a liberdade é enquanto necessidade presente". ${ }^{8}$ Dessa dimensão capital do que mais tarde denominar-se-á "espírito objetivo", pode-se dizer que é ao escrever a Fenomenologia que Hegel toma filosoficamente consciência, notadamente quando aparece-lhe necessário transbordar o projeto inicial de uma "ciência da experiência da consciência", o qual permanecia inteiramente dependente de uma compreensão do espírito como espírito subjetivo e orientado para uma objetividade dada, em direção a uma "fenomenologia do espírito" levando em conta tanto a objetividade como 
a subjetividade deste, o que quer também dizer a sua dimensão éticopolítica e histórica:

"Sua essência espiritual já foi caracterizada como a substância ética; mas o espírito é a efetividade ética. Ele é o Si da consciência efetiva, à qual ele [faz face], ou melhor, que se faz face como mundo efetivo ob-jetivo, que no entanto também, para o $\mathrm{Si}$, perdeu toda a significação de algo estranho, assim como o Si perdeu toda a significação de um ser-para-si dependente ou independente, separado dele $\left[=\right.$ do mundo]". ${ }^{9}$

Para apreender toda a força inovadora desse conceito de espírito, é necessário voltar um pouco atrás e examinar a transição da razão ao espírito. "A razão é a certeza da consciência de ser toda a realidade". ${ }^{10}$ Essa proposição, várias vezes declinada, é como o indicativo de todo o capítulo V. Diferentemente das figuras precedentes da consciência e da consciência de si, a razão "recebeu em partilha a paz" com o mundo, do qual ela descobre que ele é "seu mundo" ou sua própria efetividade; e é por isso que "é como se para ela o mundo fosse pela primeira vez". ${ }^{11}$ Essa é a convicção fundadora do que é nomeado aqui, em uma clara alusão às filosofias de Kant e de Fichte, "o idealismo": só há mundo para a razão, porque é ela que constitui o mundo, por exemplo ao organizar sua "diversidade" graças às suas "categorias". Hegel vai, sem dúvida, ao longo de todo o capítulo, como no Prefácio (onde o idealismo é qualificado de "dogmatismo da certeza de si mesmo"12), mostrar-se severo a respeito desse idealismo racionalista que se funda sobre um "conceito abstrato da razão"13; no entanto, não é nunca para opor-lhe um "irracionalismo" ou um anti-racionalismo (a rejeição das posições românticas no Prefácio é sem apelação, e a crítica de Jacobi em Fé e saber não perdeu nada

\footnotetext{
PhG, W3, p. 325; PhE, p. 403.

PhG, W3, p. 179; PhE, p. 253.

PhG, W3, p. 178-179; PhE, p. 253.

PhG, W3, p. 53; PhAE, p. 113.

PhG, W3, p. 185; PhE, p. 259.
} 
de sua atualidade), mas para exigir da razão que ela ultrapasse seu "mau idealismo unilateral"14, abrindo-se a este "caminho esquecido" que é sua própria historicidade, ou seja, assumindo-se como espírito. A via para chegar a isso é longa e semeada de armadilhas. Mas o fio condutor dessas análises, por vezes fastidiosas, é claro: para desfazerse desse "mau idealismo" subjetivo, que toma a efetividade na "posse universal" e "planta sobre todas as alturas e em todas as profundezas o signo de sua soberania"15, a razão deve consentir em desprender-se dela mesma, renunciar à sua "loucura da presunção" que consiste em querer impor ao mundo a "lei do coração"16. A partir do momento em que a razão compreende - o que ela faz no final das dialéticas da "razão legisprobatória" - que não se trata para ela de conferir um sentido ao mundo, com o que esse gesto comporta de violência, mas de reconhecer a racionalidade já operante nele (nas prescrições "eternas" do direito, por exemplo), logo que ela perceba que ao sair de si é ela mesma que ela encontra, "a razão é espírito":

"A razão é espírito enquanto que a certeza de ser toda realidade [é] elevada à verdade, e [que] ela é consciente dela mesma como de seu mundo e do mundo como dela mesma"17.

Assim o espírito, no sentido preciso e novo que Hegel confere a esse termo, é o produto das dialéticas da razão (subjetiva). Mais largamente, a objetivação histórica das posições da consciência, da consciência de si e da razão através dos diferentes momentos do espírito é uma sequência necessária do inacabamento próprio a essas figuras:

"Todas as figuras antecedentes da consciência são abstrações do [espírito]; elas são isto: que ele [o espírito]

\footnotetext{
14 PhG, W3, p. 181; PhE, p. 256.

15 PhG, W3, p. 186; PhE, p. 261

16 Ver PhG, W 3, p. 275 s.; PhE, p. 351 s. Hegel, nesta passagem, inspirou-se no personagem de Karl Moor em Os Salteadores de Schiller; mas pode-se igualmente pensar em Michael Kohlhaas de Kleist, pronto para pôr fogo no mundo e a derramar sangue para reparar uma injustiça sofrida.

17 PhG, W3, p. 324; PhE, p. 402.
} 
se analisa, diferencia seus momentos e se demora nos [momentos] singulares. Esse ato de isolar momentos desta sorte o tem, ele mesmo [= o espírito], por pressuposição e por subsistir, ou esse [momento] só existe nele, que é a existência. Eles têm, assim isolados, a aparência de serem enquanto tais; mas como eles são apenas momentos ou grandezas evanescentes, eis o que mostrou seu impulso para a frente e [seu] retorno em seu fundamento e essência; e essa essência é justamente esse movimento e [essa] dissolução desses momentos"18.

Há, no entanto, uma decalagem inegável, um salto mesmo entre o espírito e os precedentes corpos de figuras reagrupadas sob o comando da consciência, da consciência de si e da razão. Estas permanecem estruturadas pela separação do sujeito e do mundo ao qual ele se refere, incluindo aí até as últimas formas da universalização racional desta relação com o mundo; é por isso que o desnivelamento entre "certeza" e "verdade" da experiência subjetiva aí reaparece constantemente, e com ele o risco de uma Entfremdung, de uma alienação no sentido forte de desprendimento absoluto de si, de perda radical de sentido. Por outro lado, o espírito é a subjetividade que se prova como mundo objetivo, "o indivíduo que é um mundo"19: uma razão objetivada nas "figuras de um mundo" do qual cada uma é um "mundo ético vivo"20. Por isso as figuras do espírito não serão mais "figuras da consciência única", mas "figuras de um mundo", os "espíritos reais"21. Todas as figuras estudadas no capítulo do espírito, às quais não é difícil de fazer corresponder períodos da história mundial (a cidade grega, o Império romano, a cristandade medieval, a era do absolutismo, as Luzes em luta contra a "superstição", a Revolução e o Terror), pertencem portanto ao que o sistema denominará o espírito objetivo, enquanto que aquelas

\footnotetext{
PhG, W3, p. 325-326; PhE, p. 404.

PhG, W3, p. 326; PhE, p. 405.

Ibid.

PhG, W 3, p. 326; PhE, p. 405.
} 
[as figuras] da consciência, da consciência de si e da razão participam do espírito subjetivo (constituindo na Enciclopédia a subdivisão "Fenomenologia do Espírito"). Mas essas sequências históricas não são analisadas na Fenomenologia sob o mesmo ângulo que nos escritos sistemáticos ulteriores. Em particular, o propósito de seu capítulo VI não constitui uma filosofia da história: as grandes fases da história universal, que são aqui evocadas, o são enquanto elas correspondem cada qual a uma maneira especifica que o espírito tem de objetivar sua consciência e sua consciência de si em uma "razão que nele é efetiva, e que é seu mundo"22. Trata-se então de mostrar que as formas da subjetividade que foram estudadas nos capítulos precedentes são na verdade portadas e chamadas por um movimento histórico e encarnam-se em universos ético-políticos que enunciam sua verdade. O espírito, como toda a carga de objetividade que comporta, é a pressuposição das figuras da consciência subjetiva (no sentido amplo, incluindo consciência de si e razão); é por isso que "todas as figuras antecedentes da consciência são abstrações desse espírito" 23 . Mas isto não vale apenas para as formas da subjetividade finita que foram estudadas nos capítulos precedentes, mas também para o espírito absoluto ele mesmo, cuja "autoconsciência efetiva" é o "fim e resultado" do processo objetivo do espírito ${ }^{24}$, e que o Prefácio indica que ele é de certo modo, em sua verdade filosófica, levado à luz pela história ${ }^{25}$. O processo do espírito, até a última figura do perdão do Mal através do "Sim que reconcilia"26, é então, ao mesmo tempo, para trás, a pressuposição das figuras da subjetividade finita e, para frente, a antecipação e a manifestação no ser-aí histórico do espírito absoluto: "A palavra da reconciliação é o espírito sendo-aí, [...] um reconhecer recíproco que é o espírito absoluto" 27 . Por conseguinte, a

\footnotetext{
22 Ibid.

23 PhG, W3, p. 325; PhE, p. 404.

24 PhG, W3, p. 327; PhE, p. 406.

25 Ver $P h G, W 3$, p. 18; PhE, p. 75.

26 PhG, W3, p. 494; PhE, p. 580.

27 PhG, W3, p. 493; PhE, p. 579.
} 
passagem do ponto de vista da subjetividade consciencial ao [ponto de vista] do mundo histórico do espírito é, correlativamente à radicalização do ponto de vista da primeira nas diversas formas da subjetividade religiosa (capítulo VII), o que abre a via à reconciliação absoluta do que é em si e do que é para a consciência: ao saber filosófico, que se expõe ao estado "puro" no sistema.

Assim, a transição da consciência subjetivo-objetal (entendamos: uma consciência que se determina como subjetividade engajada em uma relação constitutiva com a objetividade) para o espírito objetivo (entendido como sistema de configurações históricas e institucionais portando a reivindicação de autonomia dos sujeitos ao mesmo tempo em que ele a confina em estritos limites) não esgota o teor do conceito "multiplicado" de espírito que desenvolve a Fenomenologia. O que o livro também mostra, em seus dois últimos capítulos, é a necessidade que conduz do "espírito em seu mundo" ao "espírito consciente de si como espírito"28 e permite retomar a historicidade inerente ao espírito objetivo (considerando que tal seja objeto do capítulo VI, o que será necessário nuançar) na eternidade do espírito absoluto, pensando a reunião ou a unificação das duas reconciliações do espírito com ele mesmo: a reconciliação "histórica" e a reconciliação "religiosa"29. Mas para estabelecer este resultado, que corresponde ao ponto de vista mesmo do saber absoluto, é necessário precisamente todo o caminho da Fenomenologia. E esse caminho é longo e tortuoso, ele supõe a "paciência do conceito" celebrada pelo Prefácio:

"A impaciência requer o impossível, ou seja, a obtenção do fim sem os meios. De um lado, temos de suportar a extensão desse caminho, porque cada momento é necessário; de outro lado, há que demorar-se em cada momento, porque cada um é ele mesmo uma figura individual total e só é considerado de modo absoluto na medida em que

\footnotetext{
$28 \quad P h G, W 3$, p. 497; PhE, p. 585.

29 PhG, W3, p. 579; PhE, p. 678-679.
} 
sua determinidade for considerada como todo ou [como] concreto, ou o todo na característica dessa determinação"30.

Pode-se assim falar, com Rosenkranz, de uma "crise fenomenológica do sistema"31. Essa crise foi decisiva, já que ela provocou a ruptura de Hegel com o estilo filosófico e a linguagem filosófica de Schelling, bem como de Fichte, que ele tinha até então praticado. Na sua proliferação, sem dúvida inesperada, a Fenomenologia é o ato de uma tomada de consciência por Hegel de sua originalidade filosófica, e esta se expressa de forma concentrada no conceito inédito de espírito que esse livro elabora. Se é verdadeiro que seu objeto inicial, como é dito na Introdução, é expor a série necessária das "figuras da consciência" até a reconciliação do "fenômeno" (o que aparece à consciência) e da "essência", dando acesso ao "reino total da verdade"32, e se essa reconciliação é reconhecida como tal no saber absoluto que unifica de modo mediatizado o espírito e a consciência que ele tem dele mesmo, é necessário acrescentar - é o que Hegel descobre ao redigir o livro, mas essa descoberta resulta de todos os seus trabalhos anteriores que a realização dessa reconciliação exige que seja ultrapassada a definição inicial de espírito, puramente consciencial ou subjetiva no sentido recebido da palavra, e que se "demore", segundo a expressão à qual recorre várias vezes o Prefácio ${ }^{33}$, no exame das formas do desdobramento histórico do que se denominará ulteriormente o espírito objetivo. "A experiência da consciência", tal como ela é consignada nos primeiros capítulos, é sobrecarregada, do ponto de vista retrospectivo da Ciência filosófica (ponto de vista que antecipa, no curso do processo fenomenológico, a distinção entre o que é "para a consciência" e o que é "para nós"), de um afastamento persistente entre o que é "para ela" e o que é "em si"; ela implica então, pela sua própria necessidade, uma

\footnotetext{
30 PhG, W3, p. 33; PhE, p. 91.

31 K. Rosenkranz, Vie de Hegel, Paris: Gallimard, p. 338: trata-se do título do capítulo consagrado à Fenomenologia. ${ }^{32}$

PhG, W 3, p. 80-81; PhE, p. 145.

33 Ver PhG, W3, pp. 13, 16, 32, 33, 36; PhE, pp. 70, 73, 90, 91, 94.
} 
elevação ao elemento de sua própria universalidade, ou seja, ao "saber absoluto". E este não é, isso é agora entendido, "o absoluto do saber" 34 , mas antes o que eu chamo uma "posição de saber", uma posição caracterizada pela Aufhebung [suprassunção], em todos os sentidos da palavra, das dualidades conscienciais e, mais largamente, daquelas que afetam o espírito em sua finidade.

\title{
O direito no sistema e na Fenomenologia
}

Na Fenomenologia do Espírito, trata-se certamente muito do direito e, mais ainda, da lei, mas de um ponto de vista bem diferente daquele da doutrina do espírito objetivo, então ainda em gestação. Na Enciclopédia ou nas Grundlinien, é enquanto manifestação da "liberdade objetiva" ou como ato da "vontade objetiva" que o direito é analisado. O que isso significa? Eis como a Introdução das Grundlinien define o direito:

\begin{abstract}
"O terreno do direito é, de maneira geral, o espiritual, e sua situação e seu ponto de partida mais preciso são a vontade que é livre, de modo que a liberdade constitui sua substância e sua destinação, e que o sistema do direito é o reino da liberdade efetuada, o mundo do espírito produzido a partir do espírito ele mesmo, enquanto segunda natureza" ${ }^{35}$.
\end{abstract}

Devemos reter desta passagem e do $\S 486$ da Enciclopédia, que Ihe é paralela, que existe entre liberdade, vontade e direito uma equação forte. Acrescentemos que essa equação permite definir a posição do que Hegel nomeia, com uma expressão que ele forja, o espírito objetivo.

Que significa essa conjunção da liberdade, da vontade, da objetividade e do direito? Na filosofia hegeliana, tais conceitos têm um

\footnotetext{
34 Para transpor em contexto fenomenológico um propósito de P.-J. Labarrière relativo à Enciclopédia: ver “L'esprit absolu n'est pas l'absolu de l'esprit: de l'ontologique au logique”, in G. Jarczyk e P.-J. Labarrière, Hegeliana, Paris: PUF, 1986, p. 294 s.

$35 \quad R P h, W 7, \S 4$, p. 46; $P P D$, p. 119-120. Ver igualmente $R P h, W 7, \S 29$, p. 80 (PPD, p. 138): "Que um ser-aí em geral seja o ser-aí da vontade livre, tal é o direito. - Ele é, por conseguinte, de maneira geral, a liberdade enquanto ideia".
} 
teor que não corresponde à maneira comum de entendê-los. Hegel distingue claramente - já era o caso de Kant, na Doutrina do direito em todo caso- a vontade (der Wille) e o arbítrio (die Willkür): o arbítrio, como poder de escolha entre possíveis dados, é apenas um momento, um momento de extrema tensão, da vontade, concebida como pura potência de autodeterminação racional: "O arbítrio, em vez de ser a vontade em sua verdade, é antes a vontade como contradição"36. Além disso, Hegel rejeita constantemente a definição kantiana do direito como limitação da vontade (ou do arbítrio) de cada um segundo uma regra universal; uma tal definição, com efeito, toma por princípio primeiro do direito a vontade ou, antes, o arbítrio do indivíduo singular, e não a vontade racional, a vontade "em si e para si"; ela comporta assim um déficit de universalidade irremediável. Por último, é necessário insistir na originalidade da concepção hegeliana de uma liberdade objetivada, "configurada na efetividade de um mundo" e recebendo, assim, "a forma da necessidade"37: definida de modo geral como Beisichsein im Anderen ou como "ato de reunir-se no Outro consigo mesmo"38, a liberdade não pode ser entendida como um predicado de uma subjetividade fechada em si mesma e presumida originária, ela é antes um processo de objetivação de que resulta um sistema de configurações institucionais que pressupõe em definitivo a constituição de uma interioridade "subjetiva". Uma noção como a de "vontade objetiva"39, que constitui à primeira vista um oximoro, é a ilustração dos deslocamentos que supõe a definição hegeliana do direito como "ser-aí da vontade livre". Do ponto de vista do sistema, a subjetividade finita (o espírito subjetivo) pressupõe o espírito objetivo que é o quadro institucionalizado de seu livre desdobramento. Hegel nos indica claramente que esse desdobramento é historicamente situado, e que, por conseguinte, o "sujeito" é um produto do mundo

\footnotetext{
$R P h, W 7, \S 15$ A., p. 66; PPD, p. 129.

Enzykl, W 10, § 484, p. 303; Encycl 3, p. 282.

Enzykl, W 8, § 159 A., p. 305 ; Encycl 1, p. 405.

Enzykl, W 10, § 486, p. 304; Encycl 3, p. 283.
} 
moderno: "o direto da liberdade subjetiva constitui o ponto de inflexão e o ponto central da diferença entre a Antiguidade e a época moderna" 40 . Não apenas o "sujeito", aliás, mas também suas figuras objetivadas, em particular sua transcrição jurídica, o direito à propriedade pessoal ${ }^{41}$. Mas se o espírito subjetivo pressupõe o espírito objetivo, um e outro, enquanto configurações finitas, são tributários, quanto ao seu sentido último, do espírito infinito ("absoluto"), que tem de ser entendido menos como uma coisa ou um ser (mesmo que supremo) do que como o processo engendrando continuamente o espírito finito em suas duas dimensões objetiva e subjetiva. Afinal de contas, é enquanto auto-dicção racional do espírito absoluto que a filosofia pode pensar o engendramento da subjetividade ou do espírito finito no quadro institucional (jurídico, social, político) do espírito objetivo.

É em vão, eu já disse isso, buscar qualquer paralelismo entre o propósito da doutrina sistemática do espírito objetivo e o [propósito] da Fenomenologia. Este representa antes um "corte" daquele segundo um ângulo de visão bem particular: o que permite declinar, até ao "saber absoluto" que a supera dando ao mesmo tempo conta, a "cisão da consciência" entre verdade - digamos: a orientação para a objetividade, entendida como medida da verdade do saber - e certeza - digamos: a imagem que a subjetividade tem dela mesma no momento em que assume e realiza a separação "originária" do sujeito e do objeto, da certeza e da verdade. Na Fenomenologia, trata-se de pensar o "saber absoluto" (a posição do saber filosófico) como resultado (na verdade, ele é antes a pressuposição) das dialéticas da consciência e do espírito; ao contrário, o sistema, exposto pela Enciclopédia, parte da "decisão de filosofar", portanto da posição de certa forma dada do "saber puro", tal como o nomeia a Lógica, para desdobrar progressivamente

$R P h, W 7, \S 124$ A., p. 233; $P P D$, p. 221.

41 Ver $R P h, W 7, \S 62$ A., p. 133 (PPD, p. 169): "Já faz mil e quinhentos anos que a liberdade da pessoa começou a florescer graças ao cristianismo e que ela tornou-se um princípio universal entre uma parte, pequena aliás, do gênero humano. Mas é desde ontem, por assim dizer, que a liberdade da propriedade foi reconhecida aqui e ali como princípio". 
o conjunto das configurações lógicas e "reais" (reais no sentido em que a Enciclopédia qualifica as filosofias da natureza e do espírito de "ciências reais" face à "ciência da ideia pura" que é a Lógica) que são a expressão efetiva, a atualização dessa posição de saber inicial (o "começo da ciência"). Por conseguinte, quando se trata do direito (ou antes da lei, das Gesetz) na Fenomenologia, nunca é do ponto de vista do saber puro desdobrado em sistema da ciência, mas apenas na medida em que a consciência está na necessidade, pelas suas regras próprias, de se relacionar ou de relacionar seu objeto com uma configuração de legalidade que, muitas vezes, Ihe aparece como um "dado" indisponível, por exemplo como o "curso do mundo" ao qual a "virtude" tenta em vão se opor ${ }^{42}$. Para dizê-lo em uma palavra: a lei, na Fenomenologia, participa de uma economia da separação - da certeza e da verdade, da consciência e do mundo - enquanto que, nas Grundlinien, ela é sempre uma instância de reconciliação, enquanto "forma da racionalidade" que se dão "o direito e a eticidade", enquanto "razão da Coisa"43 para a qual apenas "o fanatismo, a imbecilidade e a hipocrisia" 44 podem sonhar em se opor, aliás em vão. No sistema, o direito é a instância de objetividade graças à qual, a pessoa, o sujeito, o membro do grupo familiar, o burguês, o homem, o cidadão - tantas figuras sucessivas da subjetividade na ordem do espírito objetivo ${ }^{45}$ adquirem uma consistência; na Fenomenologia, ele é esse muro de objetividade contra o qual a consciência de si vem esterilmente chocarse, enquanto ela não compreendeu ou experimentou que isso com que ela se defronta, na verdade, é ela mesma, ou sua própria finidade.

\footnotetext{
Ver PhG, W3, p. 283 s.; PhE, p. 360 s.

$R P h, W 7$, Vorrede, p. 20; PPD, p. 99.

$R P h, W 7, \S 258$ A., p. 402; $P P D$, p. 337.

Ver $R P h, W 7, \S 190$ A., p. 348; PPD, p. 287.
} 


\section{Aquém e além do direito: a violência e a história}

Estranhamente, pelo menos à primeira vista, o vocabulário do direito está praticamente ausente das passagens onde talvez mais se esperasse encontrá-lo. Esse é, primeiro, o caso do que se conhece sob o título infeliz de "dialética do senhor e do escravo": o primeiro momento do capítulo IV, intitulado "Selbstständigkeit und Unselbstständigkeit des Selbstbewusstseins; Herrschaft und Knechtschaft [Independência e dependência da autoconsciência; Senhorio e servidão]"46. Por que essa ausência é surpreendente? Porque, caso se adote uma interpretação como a de Kojève, se, "independentemente do que pensa Hegel, a Fenomenologia é uma antropologia filosófica"47 e se a dita dialética do senhor e do escravo descreve o "processo histórico, antropogênico" graças ao qual se constitui "um Mundo não-natural, um Mundo cultural, histórico, humano"48, compreende-se dificilmente que o direito não encontra aí seu lugar, ao menos como resultado dessa dialética da qual o não-direito (a violência, se quisermos) é o motor. Esse é, no entanto, o caso. E essa ausência nos ensina mesmo algo de essencial no que concerne ao direito: na ausência de reconhecimento - e só há reconhecimento recíproco, porque um reconhecimento "unilateral e desigual"49 não pode conduzir a verdadeiras relações de direito entre

Nota dos Tradutores: Kervégan traduz este título da primeira divisão do capítulo IV: "Autostance [indépendance] et inautostance [dépendance] de l'autoconscience: maîtrise et servitude". Autostance, inautostance são neologismos franceses para traduzir respectivamente Selbständigkeitl Unselbständigkeit, e foram criados por Pierre-Jean Labarrière e Gwendoline Jarczyk em sua tradução da Fenomenologia do Espírito pela Gallimard em 1993: Selbständigkeit designaria, para Jarczyk e Labarrière, "uma realidade que "se tem em pé" (Stand / stehen) como um Si" (PhE, p. 57), ou o que literalmente "está em pé por si". Labarrière já perguntava, em 1992: "(...) ce qui fait qu'une réalité "se tient en soi comme un Soi", pourquoi ne pas l'appeler son "auto-stance"? Un concept qui recouvre par exemple le sens du terme allemand Selbständigkeit, et qui n'a pas d'équivalent exact dans notre langue", L'utopie logique (Paris: L'Harmattan, 1992), p. 120; e ele tentou familiarizar esse vocábulo (que não pode ser confundido com a autonomia no seu sentido kantiano de Selbstgesetzgebung) e legitimar seu uso no terceiro capítulo do seu livro: Au fondement de l'éthique. Autostance et relation (Paris: Kimé, 2004), p. 45-55. Ver Th. Calvet de Magalhães, "The concept of recognition in Hegel's Phenomenology of Spirit. Labarrière reading Hegel (Portuguese version)" https://www.academia.edu/5582804/The_concept_of_recognition_in_Hegels_Phenomenology_of_ Spirit._Labarri\%C3\%A8re_reading_Hegel_Portuguese_version_(p. 2-3).

47 A. Kojève, Introduction à la lecture de Hegel, Paris: Gallimard, 1947, p. 39.

48 Kojève, op. cit., p. 30-31.

49 PhG, W 3, p. 152; PhE, p. 224. 
pessoas verdadeiramente independentes, livres - não há direito, nem direitos. O senhor não tem direitos sobre o servidor, quando muito uma "potência absoluta"50; quanto ao servidor, não é em nome dos direitos eternos do homem que ele se volta contra a tirania do senhor, não são direitos de que ele recupera o gozo graças ao poder "formador" do trabalho, mas "uma liberdade que permanece ainda no interior da servidão" ${ }^{1}$. É somente além (um além ao mesmo tempo histórico e lógico) do "obscuro combate pelo reconhecimento", e uma vez assegurada a reciprocidade do reconhecimento do homem pelo homem, o que só é possível no seio de uma ordem jurídica e política constituída (mesmo que se trate de uma ordem injusta), que se pode tratar de direito e até mesmo do "combate pelo direito", segundo a expressão de Ihering. Hegel o indica, muito claramente, na passagem da Enciclopédia que "corresponde" à dialética senhorio/servidão, a "violência" do combate pelo reconhecimento é sem dúvida a origem, mas ela não é o princípio ou o "fundamento" do direito e do Estado:

"O combate do reconhecimento e a submissão a um senhor são o fenômeno no seio do qual surgiu a vida em comum dos homens, como um começo dos Estados. A violência, que, nesse fenômeno, é [o] fundamento, não é no entanto [o] fundamento do direito, embora seja o momento necessário e justificado na passagem do estado da consciência de si submersa no desejo e na singularidade ao estado da consciência de si universal. É aí o começo exterior, ou o começo no fenômeno, dos Estados, não seu princípio substancial"s2.

Assim, a figura "Senhorio e servidão" comporta um ensinamento essencial quanto ao direito: só pode se tratar de direto, de reivindicação

50 PhG, W3, p. 153; PhE, p. 225.

51 PhG, W3, p. 155; PhE, p. 227.

52 Enzykl, W 10, § 433 A., p. 223; Encycl 3, p. 231. Hegel esclarece no seu curso: "o combate pelo reconhecimento só pode ter lugar no estado de natureza [...] ao contrário, está longe da sociedade civil e do Estado, porque, aqui mesmo, o que constitui o resultado de tal combate - a saber o ser-reconhecido - já está presente" (Enzykl, W 10, § 432 Z., p. 221; Encycl 3, p. 533). 
ou de conquista de direto(s), lá onde se encontra ao menos garantido um reconhecimento mútuo de sua humanidade pelos homens, a saber, em uma sociedade, ou melhor, em um Estado constituído, e não "antes do começo da história efetiva" ${ }^{3}$. Não é então surpreendente que, na Fenomenologia ela mesma, quando se trata do direito ou da lei (pelo menos no sentido jurídico do termo, o que não é o caso na longa análise da razão observadora que "revolve todas as entranhas das coisas e Ihes abre todas as veias para poder surgir dali ao encontro de si"54), seja sempre a propósito da Sittlichkeit e das relações complexas que a consciência ou a consciência de si subjetivas mantêm com ela: no capítulo $\mathrm{V}$, a passagem que trata da "efetuação da autoconsciência racional por ela mesma", e mais precisamente as figuras "A lei do coração e o delírio da presunção" e "A virtude e o curso do mundo" e, no terceiro momento do capítulo, "A razão legisladora" e "A razão legisprobatória"; o conjunto do capítulo VI, mas em particular seu primeiro momento, "O espírito verdadeiro. A eticidade"; enfim, no capítulo VII, a passagem consagrada à "religião de arte". Tentaremos ulteriormente tirar alguns ensinamentos dessa presença insistente da lei ética no processo fenomenológico, enquanto este é bem o do espírito em todas suas dimensões e não apenas da consciência ou consciência de si subjetiva.

Segundo exemplo de ausência significativa da linguagem do direito: a análise da Revolução francesa na figura "A liberdade absoluta e o Terror". Nessa análise, extremamente crítica, do processo revolucionário e de seu arrebatamento "terrorista", não se trata do direito, e muito pouco da lei. Esta quase ausência deve nos instruir. Sabemos, com efeito, que a análise hegeliana da Revolução está longe de ser unilateralmente negativa. O velho Hegel declara, por exemplo, em seus cursos sobre a filosofia da história:

"O pensamento, o conceito do direito se fez de repente valer e o velho edifício do não-direito não pôde lhe opor nenhuma

\footnotetext{
$53 \quad R P h, W 7, \S 349$ A., p. 507; PPD, p. 436.

54 PhG, W3, p. 186; PhE, p. 261.
} 
resistência. No pensamento do direito, construiu-se, portanto, então uma constituição, tudo devendo doravante repousar sobre essa base [...] Foi, portanto, uma aurora magnífica. Todos os seres pensantes concelebraram essa época"55.

Em suas lições [Leçons sur la philosophie de l'histoire], Hegel apresenta, portanto, a Revolução como uma revolução do direito e dos direitos do homem (o texto contém uma referência explicita à Declaração de 1789), e também como uma revolução constitucional, os dois aspectos estando evidentemente ligados em seu espírito. Sem dúvida, a sequência do curso [sobre a filosofia da história] contém uma crítica do curso ulterior da Revolução, e notadamente do episódio do Terror; mas essa crítica é feita com base em uma adesão sem reserva ao princípio da Revolução como revolução do direito.

Como explicar a diferença de tonalidade entre as afirmações feitas em 1830 (quando Hegel tornou-se, dizem, muito mais conservador do que em sua juventude e que ele se inquieta como os distúrbios revolucionários que se produzem na França) e o texto da Fenomenologia? Muito simplesmente considerando que "A liberdade absoluta e o Terror" não desenvolve uma análise da Revolução, mas apenas de seu episódio paroxístico de 1793. É por essa razão que não se trata aí do direito nem dos direitos do homem, mas apenas do processo pelo qual, levada ao absoluto, a liberdade incapaz que é, então, de nenhum "ato positivo", se volta contra ela mesma em uma "fúria do desaparecer"56 cujo único resultado é "a morte mais baixa, mais fria, sem mais significação do que cortar uma cabeça de couve" 57 . Não é o princípio da Revolução - e esse princípio é, sem ambiguidade, o direito em toda sua majestade - mas seu curso que é analisado, e mais precisamente sua fixação no momento do negativo que ele comporta como todo processo. Importa aqui rememorar

\footnotetext{
55 Weltgeschichte, $W 12$, p. 529; ver Histoire, p. 340.

56 PhG, W3, p. 435-436; PhE, p. 520.

57 PhG, W3, p. 436; PhE, p. 521.
} 
a distinção que Hegel faz entre o negativo e a negatividade. Quando ele glorifica no Prefácio "a potência espantosa do negativo" e acentua que é necessário "olha[r] esse negativo em frente e se demora[r] junto dele", porque esse demorar-se é "o que converteu [o negativo] em ser"58, é bem a fecundidade da negatividade, entendida como momento de mediatização dialética do processo lógico-especulativo, que ele quer louvar. Tanto a negatividade, entendida como dinamismo processual, como instância do "negativamente racional" fecundando a positividade imediata e favorecendo o acesso ao ponto de vista especulativo ou positivamente racional, é fecunda ${ }^{59}$, quanto a parada no momento do negativo comporta o risco de um bloqueio - o que é bem outra coisa que uma "freagem", uma Hemmung - do processo dialético. É esse perigo que ilustra a parada da liberdade no seu momento negativo, "absoluto". Mas essa parada, por mais dolorosa que seja, é apenas um momento convulsivo de um processo que, posto de novo em movimento, supera o "terror puro do negativo". A história não para por muito tempo e o espírito, que é o sujeito dela, nutre-se daquilo que a fixou: "a morte desprovida de significação, a negatividade não-preenchida do Si, oscila [...] para a positividade absoluta"60.

As duas passagens que eu acabo de evocar, "Senhorio e servidão" e "A liberdade absoluta e o Terror", comportam, portanto, tratando-se do direito, um ensinamento pelo menos negativo. Sua ausência desses momentos de violência absoluta, muda, que são o combate pelo reconhecimento e o Terror, mostra que o direito pertence a uma economia positiva, a da liberdade e da história. Não há direito nem "antes do começo da história efetiva" nem quando o processo histórico se fixa no seu momento negativo. Importa agora, por contraste

\footnotetext{
$58 \quad$ PhG, W3, p. 36; PhE, p. 94.

59 Ver, a propósito dos três "momentos de tudo o que tem uma realidade lógica", Enzykl, W 8, § 79 -82, p. 168-177; Encycl 1, p. 342-344.

$60 \quad$ PhG, W 3, p. 440; PhE, p. 524.
} 
com essas duas "situações extremas", examinar as figuras positivas do direito no processo da Fenomenologia.

\section{Figuras fenomenológicas do direito}

A introdução do segundo tempo do capítulo V, "Certeza e verdade da razão", é toda ela dedicada a expor os problemas que põe a ideia de Sittlichkeit, problemasque,énecessárioacentuar, nãoencontramqualquer solução satisfatória e imanente no quadro da Fenomenologia do Espírito, o que é em si mesmo instrutivo. Com a ideia de um reconhecimento mútuo das consciências de si, de uma "autoconsciência reconhecida que na outra autoconsciência livre tem a certeza de si mesma, e aí sua verdade", abre-se, escreve Hegel, "o reino (Reich) da eticidade"61. Isso confirma a indicação negativa fornecida pela apresentação do combate pelo reconhecimento: somente um reconhecimento mútuo (que não é evidentemente exclusivo de desigualdades de todas as ordens, mas de desigualdades sobre fundo de similitude essencial dos dominantes e dos dominados) abre o espaço da interação comunicativa, isto é, da política. A Sittlichkeit, que "não é outra coisa que, na efetividade independente dos indivíduos, a unidade espiritual absoluta de sua essência"62, adota as duas figuras indissociáveis da lei (que expressa sob modo universal a unidade compacta da "substância" ética) e dos costumes (que são como a prática vivida dessa unidade por indivíduos). Essa ideia da Sittlichkeit se realiza na "vida de um povo", e mais precisamente de um povo livre no sentido grego (político) do termo. Hegel o explicita nos seguintes termos:

"Assim como o indivíduo-singular, em seu trabalho singular, já realiza inconscientemente um trabalho universal, do mesmo modo ele realiza o trabalho universal como seu objeto consciente; o todo se torna como todo sua obra, pela

\footnotetext{
61 PhG, W3, p. 264; PhE, p. 340.

62 PhG, W3, p. 264; PhE, p. 340.
} 
qual ele se sacrifica, e por isso mesmo dele se recebe [ele mesmo] de volta. Não há nada aqui que não seja recíproco [...] Essa unidade do ser para outra coisa, ou do fazerse coisa, com o ser para si, essa substância universal fala sua linguagem universal nos costumes e nas leis de seu povo [...] É, portanto, em um povo livre que a razão em verdade está efetivada; ela é espírito vivo presente, no qual o indivíduo encontra sua destinação, isto é, sua essência universal e singular, não apenas enunciada e dada aí como coisidade, mas é ele mesmo essa essência, e alcançou também sua destinação. Por isso, os homens mais sábios da Antiguidade produziram este enunciado: que a sabedoria e a virtude consistem em viver de acordo com os costumes de seu povo"63.

Esta descrição do que é a Sittlichkeit de um povo livre se conforma com as expectativas que são as do jovem Hegel quando ele define as condições de uma restauração da "bela totalidade" ético-política grega; ela participa plenamente, à primeira vista, dessa nostalgia da Grécia que se expressava tão fortemente nos escritos de Berna, de Frankfurt e nos escritos anteriores do período de Jena, como o artigo sobre o direto natural e o System der Sittlichkeit. A individualidade verdadeira reside no sacrifício da individualidade no sentido moderno, "burguês", do termo, na renúncia à busca da felicidade ou do bem-estar pessoal, na adesão sem restrições aos valores da comunidade, tais como eles são depositados nas leis e nos costumes. Parece, portanto, que estamos inteiramente aqui no que Hyppolite denominou a "concepção heróica da cidadania" do jovem Hegel ${ }^{64}$.

No entanto, a sequência do texto mostra que essa concepção sofre uma profunda vacilação, que vai a curto prazo (se isso de fato já não se

\footnotetext{
63 PhG, W3, p. 265-266; PhE, p. 341-342.

64 Ver J. Hyppolite, "La première philosophie du droit de Hegel", in Introduction à la philosophie de l'histoire de Hegel, Paris: Seuil, 1983, p. 94 s.
} 
realizou) conduzir ao seu abandono. Depois de ter definido a Sittlichkeit em termos enfáticos e acentuado a "felicidade" (uma felicidade política e comunitária, bem diferente da felicidade egoísta dos modernos) que ela proporciona ao indivíduo, Hegel acrescenta:

"Mas dessa felicidade de ter alcançado sua destinação e de viver nela, a autoconsciência, que de início só era espírito imediatamente e segundo o conceito, saiu ou então - ela ainda não a alcançou [...] A razão tem de sair dessa felicidade; pois é somente em si, ou imediatamente, que a vida de um povo livre é a eticidade real [...] Ou então a autoconsciência ainda não alcançou essa felicidade, de ser substância ética, o espírito de um povo. Pois [...] inicialmente o espírito enquanto tal ainda não se efetivou por si mesmo; ele foi posto somente como essência interior ou como abstração"

"A razão tem de sair dessa felicidade". Com efeito, como o acentua a segunda Filosofia do Espírito, contemporânea da redação da Fenomenologia, o "princípio superior dos Tempos modernos" exige que a individualidade não seja apenas um acidente da substância ética, da "bela vida pública", que ela não se apague inteiramente diante da exigência de uma "unidade imediata do universal e do singular"66. E o que torna possível essa dissociação do singular e do universal, necessária mediação negativa em vista de sua reconciliação verdadeira, é o conjunto dos mecanismos daquilo que Hegel chama o sistema das necessidades, em outras palavras, a existência, toda moderna ${ }^{67}$, de uma "sociedade civil" relativamente autônoma no que diz respeito à instância política do universal, do Estado. Assim, a "bela e feliz liberdade dos Gregos, que foi e permanece tão invejada"68, deve ser doravante não

\footnotetext{
65 PhG, W3, p. 266-267; PhE, p. 342-344.

66 Philosophie de l'Esprit, p. 95.

67 Ver RPh Ilting 3, p. 565: "O desenvolvimento [da sociedade civil] intervém mais tarde que [o do] Estado, pois a sociedade civil, já que ela não é algo independente por si, não pode existir antes do Estado". Ver também HP 3, p. 593: "A liberdade civil é um momento necessário que os antigos Estados não conheciam".

68 Philosophie de l'Esprit, p. 93.
} 
abandonada, mas reconquistada através do que parece primeiro ser sua negação: a afirmação da individualidade egoísta do "burguês". Por conseguinte, a eticidade não é mais, sem dúvida, uma "obra de arte", mas a individualidade não é mais condenada a desaparecer para que exista a comunidade; ao contrário, contra o princípio da homogeneidade ética dos "povos livres" (pensemos em Esparta), é sua afirmação que vai garantir a constituição de uma eticidade mais rica, porque nutrida de sua própria negação e a tendo integrada e suprassumida.

"Ou então ela ainda não alcançou essa felicidade". Com efeito, a individualidade deve se dotar de uma "experiência ética do mundo", "buscar sua felicidade"69 e não encontrá-la de certo modo toda feita em uma bela totalidade que nada deve a seu agir nem aos seus impulsos. Essa experiência pode ser dolorosa e sacrificante, como a de Antígona fazendo a prova do que custa opor-se à "lei humana", mesmo que seja em nome da "lei divina" comandando à piedade familiar de se manifestar realizando o rito fúnebre sem o qual um defunto, o mais insubstituível dos defuntos, está privado de sua própria morte. Mas ela é necessária, se quisermos que a justiça não seja apenas "uma essência estranha encontrando-se além"70, que o "direito humano" seja efetivamente um direito. A análise da tragédia grega, que Hegel apresenta no início do capítulo $\mathrm{VI}$, sob o título "O espírito verdadeiro. A eticidade", tende precisamente a estabelecer que a insustentável tensão trágica - a da lei divina e da lei humana, da mulher e do homem, do dentro e do fora, e finalmente da cidade e do indivíduo - só pode ser superada se a rígida oposição for transformada em uma contradição produtiva entre "a ação ética" do indivíduo e as exigências legítimas da comunidade. Para Hegel, a lição do conflito trágico é que uma Sittlichkeit que só pode realizar-se "reprimindo" a afirmação de si dos indivíduos é mais do que frágil: ela está condenada a se dissolver, e a morte da individualidade (a 
de Antígona, a de Sócrates) traz a promessa da sua [própria morte ou dissolução]. Se a mulher (Antígona) é "a eterna ironia da comunidade", é porque ela simboliza não apenas os direitos dos deuses do lar e da família, mas também a irredutibilidade da individualidade, seu "direito" trágico de abalar a compacidade da ordem ética que acredita dever negá-la ou reprimi-la:

"Mas a comunidade só se pode manter pela opressão desse espírito da singularidade e, porque ele é momento essencial, na verdade ela igualmente o produz, e isso mediante a atitude opressiva [que ela adota] contra esse espírito [entendido] como um princípio hostil" ${ }^{\prime 1}$.

Todavia, a solução verdadeira do conflito não consiste evidentemente em dar todos os direitos ao indivíduo, compreendido como átomo jurídico, como pessoa. A demonstração indireta é feita na passagem do capítulo VI que vem imediatamente após a análise do "declínio da substância ética" (entendamos: da eticidade abstrata, imediata, natural): "O estado de direito" (Rechtszustand). Entende-se que essa passagem constitui uma crítica impiedosa do "formalismo" do direito romano, e ela alimentou a opinião frequentemente expressa segundo a qual Hegel seria um adversário do direito, em todo caso do que ele chama o direto abstrato, que corresponde ao direito privado dos juristas. Que não é bem assim e que "a abstração" do direito abstrato comporta aos olhos de Hegel uma incontestável positividade, eu me esforcei várias vezes de mostrar isso ${ }^{72}$. Mas eu gostaria aqui de sugerir que, mesmo nesta passagem da Fenomenologia, a atitude de Hegel em relação ao direito (e mais precisamente ao direito privado) não é unicamente negativa mesmo se, é verdade, a dimensão crítica do propósito é mais fortemente acentuada do que nos escritos de Berlim. Com efeito, o que

PhG, W3, p. 353; PhE, p. 432;

72 Ver, por exemplo, J.-F. Kervégan, "L'institution de la liberté", in Hegel, PPD, em particular p. 44-47. 
condena ao fracasso a experiência que faz a consciência na figura da pessoa é menos sua insuficiência própria (embora ela seja real: Hegel chega a escrever que "designar um indivíduo como uma pessoa é a expressão do desprezo"73) que o contraste, a contradição insuportável que existe entre a afirmação jurídica do princípio da personalidade e a afirmação política da onipotência do "senhor do mundo", "pessoa absoluta", "pessoa solitária que se contrapõe a todos"74. Justiniano nega violentamente, pelo poder sem limites que ele exerce, o princípio da ordem jurídica que ele proclama e institui de toda sua autoridade, seu ato é portanto inelutavelmente afetado por uma contradição performativa. Estimou-se por vezes que aquilo que descreve a sequência "estado de direito" da Fenomenologia, é a situação deplorável de uma sociedade civil sem Estado. Parece-me, antes, que o que aí é mostrado é a inefetividade do formalismo jurídico na ausência de uma verdadeira sociedade civil e de um verdadeiro Estado. Certamente, "a personalidade jurídica experimenta [...] sua ausência de substância"; mas é "enquanto o conteúdo que lhe é estranho se faz valer nela"75. O que consiste em dizer que o formalismo jurídico, que não tem, nele mesmo, nada de condenável, requer um conteúdo; e esse conteúdo - inexistente no caso do pretenso "estado de direito" imperial - é de ordem ética, mais precisamente de ordem social. Aliás, nas Grundlinien, o direito abstrato é indissociável da "administração do direito" (Rechtspflege) que lhe confere, no seio da sociedade civil, uma "efetividade objetiva"76.

A análise do que Hegel denomina, no capítulo VII, a "religião de arte" confirma, à sua maneira, os resultados da análise da Sittlichkeit imediata, quer seja sob sua figura "grega" (a ética como exigência de dissolução da individualidade) ou sob sua figura "romana" (o reino do direito abstrato acompanha-se da tirania política e conduz à dissolução da eticidade). A "religião de arte" - e trata-se evidentemente de algo

\footnotetext{
PhG, W 3, p. 357; PhE, p. 437.

PhG, W3, p. 357-358; PhE, p. 437.

PhG, W3, p. 358; PhE, p. 438.

$R P h, W 7, \S 210$, p. 361; PPD, p. 299.
} 
completamente outro que uma "religião da arte" ou de uma "religião estética" - é uma religião ética ou, no vocabulário de Rousseau, uma religião civil:

"Se indagamos qual é o espírito efetivo que, na religião de arte, tem a consciência de sua essência absoluta, resulta que é o espírito ético [...] Ele é o povo livre onde o ethos constitui a substância de todos, [substância] cuja efetividade e ser-aí todos e cada singular sabem como sua vontade e ato"77.

A arte grega, quer se trate da poesia, da tragédia ou da comédia, ou ainda das artes plásticas (escultura, arquitetura) e dos grandes ritos coletivos, é antes de tudo uma religião da cidade; o que ela proclama sob todas suas formas é "o direito do que é ético, que a efetividade não seja nada em si em oposição à lei absoluta"78. A individualidade (do deus, do herói, do sacerdote do deus, do "fiel" ou do adepto) é reprimida pela afirmação solene do universal, d“a” lei. Mas, ao mesmo tempo, essa arte religiosa é (assim como a filosofia que nasce com Sócrates) a prova vivida da impossibilidade de manter essa elisão da individualidade, a dos deuses como a dos homens. Afinal de contas - a comédia é, segundo Hegel, o lugar dessa reviravolta - é antes a uma "dissolução universal da essencialidade" que chega a religião de arte, e é o "princípio da singularidade separada do universal" que se afirma insolentemente, a ponto de "se arroga[r] de maneira manifesta um direito sobre a comunidade, de que é o prejuízo secreto"79. A religião de arte manifesta o declínio de um tipo de comunidade ética (uma eticidade "verdadeira", mas desprovida de "certeza" de si) fundado sobre a negação do Si singular, essa "força negativa pela qual e na qual os deuses assim como seus momentos [...] desaparecem ${ }^{80}$. Esta análise

\footnotetext{
PhG, W3, p. 512-513; PhE, p. 602-603.

PhG, W3, p. 538; PhE, p. 630.

PhG, W3, p. 543; PhE, p. 636.

PhG, W3, p. 544; PhE, p. 637.
} 
se une àquela que Hegel faz em outro lugar da República de Platão: esse livro expressa a essência mesma de uma eticidade substancial, fundada sobre a eliminação da individualidade, desse "princípio mais profundo que [...] só podia, de maneira imediata, aparecer nela como uma aspiração insatisfeita e, nisso, como um fator de corrupção, [...] a personalidade livre infinita"81. Esforçando-se por conter, por meios que chocam a consciência moderna, a afirmação desta, Platão pressente "a subversão do mundo que era iminente" ${ }^{22}$, subversão de que a invenção cristã da subjetividade será a manifestação brilhante. O ponto culminante das análises que a Fenomenologia consagra às figuras do direito é a descoberta do que Hegel denomina o "direito da liberdade subjetiva" e, com ela, de uma outra maneira de pensar o direito, o sujeito e a eticidade. Haverá, portanto, uma outra Sittlichkeit que aquela de que trata a Fenomenologia: a Sittlichkeit moderna, reconciliando subjetividade e objetividade, individualidade e universalidade, lei divina e lei humana.

\section{Lista de abreviaturas}

Encycl 1: Encyclopédie des Sciences Philosophiques, t. 1: La Science de la Logique. Tradução francesa de Bernard Bourgeois. Paris: Vrin, 1970.

Encycl 3: Encyclopédie des Sciences Philosophiques, t. 3: La Philosophie de l'Esprit. francesa de Bernard Bourgeois. Paris: Vrin, 1988.

Enzykl: Enzyklopädie der philosophischen Wissenschaften (1830), W 8, 9, 10.

Histoire: Leçons sur la Philosophie de l'Histoire. Tradução francesa de Jean Gibelin. Paris: Vrin, 1967.

81 Ph, W7, Vorrede, p. 24; PPD, p. 103.

82 Ibid. 
H: Leçons sur l'Histoire de la Philosophie, 7 volumes. Tradução francesa de Pierre Garniron. Paris: Vrin, 1971-1991.

PhG: Phänomenologie des Geistes, W3.

PhE: Phénoménologie de l'Esprit. Tradução francesa de Gwendoline Jarczyk e Pierre-Jean Labarrière. Paris: Gallimard, 1993.

Philosophie de l'Esprit: La Philosophie de l'Esprit (1805). Tradução francesa de Guy Planty-Bonjour. Paris: PUF, 1982.

PPD : Principes de la Philosophie du Droit. Tradução francesa de Jean-François Kervégan. Paris: PUF, 2003 (2ª edição).

$R P h:$ Grundlinien der Philosophie des Rechts, W7.

RPh llting 3: Vorlesungen über Rechtsphilosophie [Nachschrift Hotho, 1822/23], ed. Karl-Heinz Ilting, t. 3. Stuttgart: FrommannHolzboog, 1974.

W: Werke in zwanzig Bänden, ed. Eva Moldenhauer e Karl Markus Michel. Frankfurt/Main: Suhrkamp, 1969-1971.

Weltgeschichte: Vorlesungen über die Philosophie der Weltgeschichte, W 12.

Autores convidados. 